\title{
An individually randomized controlled trial of a mother-daughter HIV/STI prevention program for adolescent girls and young women in South Africa: IMARA-SA study protocol
}

Geri R. Donenberg ${ }^{1 *}$ (D) Millicent Atujuna ${ }^{2}$, Katherine G. Merrill', Erin Emerson', Sheily Ndwayana²,

Dara Blachman-Demner ${ }^{3}$ and Linda Gail Bekker ${ }^{2}$

\begin{abstract}
Background: South Africa has the world's largest HIV epidemic, but South African adolescent girls and young women (AGYW) acquire HIV at twice the rate of and seroconvert on average 5-7 years earlier than their male peers. Female caregivers (FC) are an untapped resource for HIV/STI prevention in South Africa and offer a novel opportunity to strengthen AGYW prevention efforts. This study will evaluate the effectiveness and cost-effectiveness of an evidence-based mother-daughter HIV/STI prevention program tested in the United States and adapted for South Africa, Informed Motivated Aware and Responsible Adolescents and Adults (IMARA), to decrease STI incident infections and increase $\bar{H} I V$ testing and counseling (HTC) and PrEP uptake in AGYW.

Methods: This is a 2-arm individually randomized controlled trial comparing IMARA to a family-based control program matched in time and intensity with 525 15-19-year-old Black South African AGYW and their FC-dyads in Cape Town's informal communities. AGYW will complete baseline, 6-, and 12-month assessments. Following randomization, AGYW-FC dyads will participate in a 2-day group workshop (total $10 \mathrm{~h}$ ) that includes joint and separate mother and daughter activities. Primary outcomes are AGYW STI incidence, HTC uptake, and PrEP uptake at 6 months. Secondary outcomes are AGYW STI incidence, HTC uptake, and PrEP uptake at 12 months, sexual behavior (e.g., condom use, number of partners), HIV incidence, and ART/PrEP adherence and intervention costeffectiveness. AGYW who test positive for a STI will receive free treatment at the study site. HIV positive participants will be referred to ART clinics.
\end{abstract}

\footnotetext{
* Correspondence: gerid@uic.edu

${ }^{1}$ Center for Dissemination and Implementation Science, Department of

Medicine, University of Illinois at Chicago, 818 S. Wolcott, Chicago, IL 60612,

USA

Full list of author information is available at the end of the article
}

(C) The Author(s). 2021 Open Access This article is licensed under a Creative Commons Attribution 4.0 International License, which permits use, sharing, adaptation, distribution and reproduction in any medium or format, as long as you give appropriate credit to the original author(s) and the source, provide a link to the Creative Commons licence, and indicate if changes were made. The images or other third party material in this article are included in the article's Creative Commons licence, unless indicated otherwise in a credit line to the material. If material is not included in the article's Creative Commons licence and your intended use is not permitted by statutory regulation or exceeds the permitted use, you will need to obtain permission directly from the copyright holder. To view a copy of this licence, visit http://creativecommons.org/licenses/by/4.0/ The Creative Commons Public Domain Dedication waiver (http://creativecommons.org/publicdomain/zero/1.0/) applies to the data made available in this article, unless otherwise stated in a credit line to the data. 
Discussion: Primary prevention remains the most viable strategy to stem new STI and HIV transmissions. HIV and STI disparities go beyond individual level factors, and prevention packages that include supportive relationships (e.g., FC) may produce greater reductions in HIV-risk, improve HTC and PrEP uptake, and increase linkage, retention, and adherence to care. Reducing new HIV and STI infections among South African AGYW is global public health priority.

Trial registration: ClinicalTrials.gov Number NCT04758390, accepted 02/16/2021.

Keywords: HIV prevention, Adolescent girls and women, South Africa, Mother-daughter intervention

\section{Background}

South Africa (SA) is home to the largest number of people living with HIV worldwide, $[1,2]$ but withinpopulation differences exist [2-4]. HIV rates are higher among women than men, $[2,3]$ adolescent girls and young women (AGYW) acquire HIV at twice the rate and seroconvert on average 5-7 years earlier than male peers, [2] and AIDS is the second leading cause of death among adolescents [5]. Moreover, AGYW account for over $67 \%$ of new HIV infections, [6] but only $15 \%$ know their status [7]. Women's HIV disparities are explained by a multiplicity of social and structural inequities that shape and constrain HIV-risk behaviors and continue to drive incident infections in SA [8-13]. Hence, multilevel prevention packages that are tailored to the local epidemiology and cultural context are likely to achieve and sustain maximum reductions in AGYW HIV-risk [1421].

Families are a relatively untapped resource in SA's HIV prevention efforts. Yet, families are uniquely positioned to support prevention, because they are the first socialization experience for adolescent sexual and reproductive health. Mothers and other important female caregivers (FC) (e.g., aunts, cousins) play a central role in AGYW's sexual behavior and development, and can be effective partners in reducing sexual risk while promoting new biomedical technologies like PrEP and HIV testing and counseling (HTC) [22, 23]. Research that optimizes uptake and adherence to PrEP and HTC in women [24] will facilitate more equitable access to all HIV scientific advances. Research in the US indicates maternal warmth and attachment, close family relationships, parental involvement and support, and positive parenting predict consistent condom use, less exposure to HIV-risk situations, and later sexual debut among adolescents [25-29]. Likewise, mother-daughter communication that is open, receptive, and comfortable is associated with less risky sexual behavior in the US [26, 30-37] and in Africa [38-43].

South African FC may serve as a catalyst for AGYW change. Despite noting parents as the best source of information about sex and general receptivity to such discussions, only $20 \%$ of SA youth receive information about sex from their parents, and almost 50\% of girls report that they could not openly discuss sexuality with their parents [44, 45]. Likewise, African mothers report needing and wanting accurate knowledge to discuss sex with their children [46]. Capitalizing on the FC-AGYW relationship, improving the quality of FC-AGYW conversations about sexual and reproductive health, teaching $\mathrm{FC}$ to use accurate information, and challenging cultural taboos that inhibit communication about sex [47] may alter the current HIV-trajectory for SA AGYW. Notably, AGYW may also be change agents for their FC who want to be positive role models for AGYW. In the process of promoting AGYW sexual and reproductive health, FC may change their own behavior (including HTC and PrEP uptake), thereby reducing their own risk for HIV.

IMARA is an evidence-supported mother-daughter ("mother" refers to any female caregiver) program based on the Social Personal framework [48] and derived from three established interventions: SISTA [49-53] and SiHLE [54] for African American women and girls respectively, and Project STYLE for teens and families in mental health care [55]. SISTA and SiHLE address the importance of relationship power and gender dynamics as drivers of HIV risk behavior. This is critical for the South African context where AGYW's first and ongoing sexual partner is typically an older male, [56] and AGYW with older partners are four times more likely to test positive for a sexually-transmitted infection (STI), [57] report transactional sex, [57] and have high HIV infection rates [58]. In addition, gender-based violence (GBV) among SA AGYW is higher than in every other region in sub-Saharan Africa, $[44,59,60]$ and is related to high rates of STI [61] and HIV-risk, [62-64] and impedes women's ability to receive HTC, link to treatment, and adhere to PrEP [65-67]. Project STYLE emphasizes parent-teen relationships and communication as protective against HIV and STI risk. A recent efficacy study of IMARA in the US [68] revealed a $43 \%$ reduction in incident STI infections at 1-year follow-up among 14-18 year-old African American girls who received IMARA compared to a time-matched health promotion program $(p=.011)$. 
Adaptation of IMARA to the South African context is important to ensure acceptability and uptake. Added content related to HTC and PrEP, two essential strategies to comprehensive HIV prevention, [69-74] will equip AGYW and FC with greater control and agency over their sexual lives [75]. Moreover, IMARA could provide a novel approach to reduce AGYW STI and HIV-risk and improve HTC and PrEP awareness, acceptability, and uptake (where appropriate) for FC and AGYW. Finally, rigorous cost evaluations of HIV and STI prevention packages are sorely needed to optimize the use of available resources. Establishing the costeffectiveness (CE) of HIV prevention packages is essential if they are to be sustained [76, 77].

In sum, SA AGYW have not benefitted equally from gains in the HIV epidemic. The unrelenting disparity of new infections in this group [78] requires an expansion of prevention options within the SA context [79]. Focusing on vulnerable populations and high-incidence locations, i.e., SA AGYW, will realize the greatest benefits in altering epidemiological trajectories [80]. While changing behavior can reduce HIV and STI acquisition, [11] research on evidence-based interventions with strong evaluation designs is lacking for AGYW, especially those capitalizing on the strengths and assets of families.

\section{Study objectives}

The purpose of this study is to test the effectiveness and cost-effectiveness of a culturally-tailored, evidencebased, HIV/STI prevention program for SA AGYW and FC. We will randomly assign 525 AGYW-FC dyads to IMARA-SA $(n=263)$ or a family-based health promotion (HP) program $(n=262)$ matched in time and intensity and compare participants on incident STI, and HTC and PrEP uptake at 6 months. Secondary objectives are to assess intervention effects on the primary outcomes at 12 months, reported non-condom use, number of partners, HIV incidence, and adherence to ART/PrEP. We will also evaluate the costs and CE of IMARA with respect to the acquisition of STI and HIV where possible, considering power limitations.

\section{Methods \\ Design}

This is an individually randomized controlled trial (RCT) of IMARA for 15-19 year-old Black South African AGYW and their FC. AGYW-FC dyads will be randomized to IMARA-SA versus a family-based HP program. All participants will complete baseline, 6-, and 12-month follow-up assessments via audio computerized assisted self-interview technology (ACASI) and provide urine to screen for three sexually transmitted infections (STI). All participants will also be offered HTC and PrEP, and where appropriate (e.g., if HIV/STI positive), will receive free care at the on-site adolescent-friendly reproductive health clinic at the Desmond Tutu Health Foundation (DTHF) and referral to public clinics.

\section{Identification and recruitment of participants}

The study will take place in Phillippi and the surrounding townships including Nyanga, Gugulethu and Khayelitsha, located in the Cape Town metropolitan. These areas are densely populated, have a high HIV burden, and are poorly resourced. Recruitment strategies include street outreach, word-of-mouth referrals, flyers, and clinic-based contacts by study personnel. The majority of the residents are Black and mixed race. We will enroll AGYW and a FC, defined as an important and influential female in AGYW's life (e.g., mother, aunt). AGYW will be: a) Black or mixed race; b) 15-19 years-old; c) residing in Phillipi and the surrounding areas who d) speak Xhosa, English, or a combination, as these are the primary regional languages. AGYW may or may not be sexually active, and information about AGYW sexual activity will not be shared with FC. FC will be: a) selected by the AGYW and agreed upon by the legal guardian; b) 24 years or older; c) living with or in daily contact with the AGYW; and d) a speaker of Xhosa and/or English. We will include HIV-infected and uninfected FC and AGYW, and AGYW or FC who become HIV+ and/or pregnant during the study may continue to participate. AGYW and FC must agree to participate as a dyad, but AGYW refusal will supersede FC consent. All participants, regardless of randomization status, will be followed for 12 months with visits conducted at 6 and 12-month intervals (Fig. 1).

\section{Randomization}

We will use a 1:1 randomization allocation to assign FCAGYW dyads to treatment arm (IMARA-SA $n=263$ or HP $n=262$ ) following the baseline assessment. The AGYW will select a colored paper from a hat that determines the family's group assignment. Assessors but not intervention staff will be blinded to treatment arm at 6and 12-month follow-up.

\section{Training interventionists (IMARA-SA and health promotion)}

Training for both conditions will last approximately 30 $\mathrm{h}$, and we will train IMARA-SA and HP interventionists separately. Interventionists will review their assigned curriculum and related training manuals. Training for both programs will stress the importance of following the manualized protocol to ensure fidelity across interventionists and of completing fidelity measurements at the end of each workshop day. Following review of the curriculum, interventionists will practice delivering each activity, taking turns serving as group leaders and 
Total N: 525 dyads

Pre-screen potential participants by inclusion and exclusion criteria.

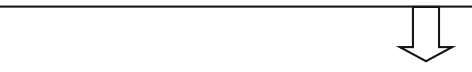

Conduct full screening and informed consent process. Administer baseline surveys.

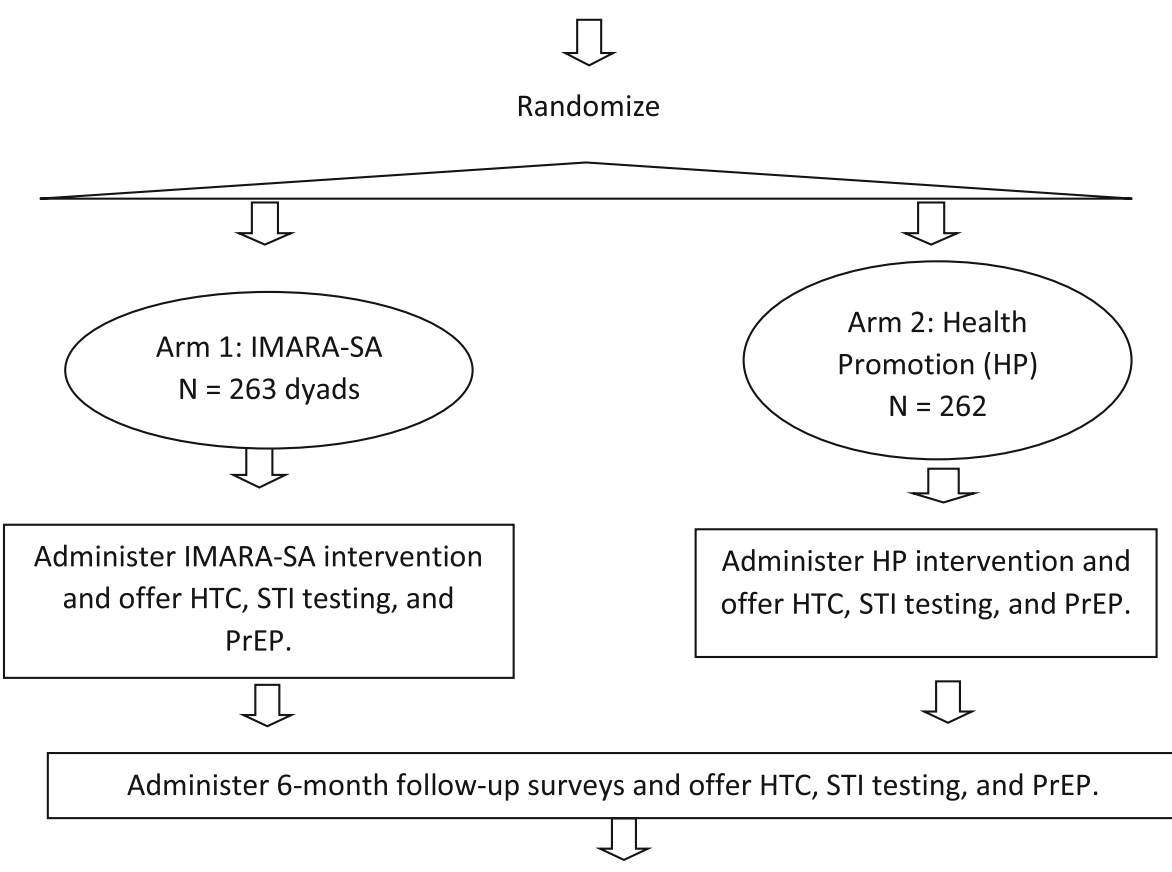

Administer 12-month follow-up surveys and offer HTC, STI testing, and PrEP.

Fig. 1 Schema for an individually-randomized controlled trial of the IMARA-SA intervention

participants. Each interventionist will be "certified" as competent to deliver IMARA-SA or the HP program by the site Principal Investigator and study sub-investigator. Refresher trainings will occur annually and as needed if observer fidelity ratings indicate drift and noncompliance.

\section{Supervision, quality assurance, and treatment Fidelity}

We will use a detailed manual and facilitator guide, conduct weekly supervision, and assess fidelity using facilitator self-report and observer ratings of adherence and competence (see below). Adherence measures will determine if the program was delivered as intended (yes/no), and competence ratings will indicate the quality of delivery. During ongoing supervision, a trained member of the study team will review fidelity reports, discuss session activities, problem-solve difficulties, and provide interventionists with feedback. If interventionists deviate from the curriculum, the supervisor will provide additional training until fidelity is achieved.

\section{Intervention delivery}

Interventionists will be South African, female, and Black or mixed race to match AGYW and FC. Both interventions will be delivered over two sessions (about $10 \mathrm{~h}$ of content). We will enroll approximately 16 dyads per cohort, and we will enroll two cohorts every 6 weeks over 24 months. We will provide breakfast and lunch on both days. All intervention activities will occur at research sites in Klipfontein/Mitchells Plain.

Description of the interventions: Informed Motivated Aware and Responsible Adolescents and adults- South Africa (IMARA-SA)

The IMARA curriculum was subject to a comprehensive and systematic adaptation process prior to this RCT. The details of the adaptation process are presented elsewhere [81]. Separate FC and AGYW groups will run simultaneously, cover parallel content, and address individual, social, and structural drivers of HIV-risk (Table 1). Joint activities are designed to enhance FC 
Table 1 IMARA-SA Curriculum

\begin{tabular}{|c|c|}
\hline Theory & Selected IMARA-SA Activities \\
\hline \multicolumn{2}{|l|}{ Individual Factors } \\
\hline $\begin{array}{l}\text { Knowledge, attitudes, beliefs, skills about } \\
\text { HIV, STI, PrEP, HTC }\end{array}$ & $\begin{array}{l}\text { Facts of HIV/AIDS/STI/PrEP/HTC; Prevalence for adolescent girls and young women; PrEP education } \\
\text { video; Perceived vulnerability; Personal risk triggers (e.g., people, places, feelings) and risk plans; } \\
\text { Demonstrate and practice condom use; De-mystifying HIV testing; Importance of regular HTC and PrEP } \\
\text { where appropriate to risk behavior. }\end{array}$ \\
\hline Mental health & $\begin{array}{l}\text { Destigmatize mental health; Links between mental health problems and HIV-risk behavior; Recognize } \\
\text { how feelings trigger risk taking; Teach healthy coping strategies; Recognize the value of the body; Sub- } \\
\text { stance use and risk taking; Referrals for counseling }\end{array}$ \\
\hline \multicolumn{2}{|l|}{ Social Factors } \\
\hline $\begin{array}{l}\text { Family context } \\
\text { Geographically constrained networks }\end{array}$ & $\begin{array}{l}\text { Importance of strong FC-AGYW relationships, open and positive communication, and FC monitoring for } \\
\text { AGYW mental health and reduced HIV/STI-risk; FC-AGYW warmth and positive interactions; Create per- } \\
\text { sonalized monitoring plans; Teach and practice effective communication with FC and family; Discuss risk } \\
\text { in the context of neighborhood and sexual networks. }\end{array}$ \\
\hline \multicolumn{2}{|l|}{ Structural Factors } \\
\hline $\begin{array}{l}\text { Gender dynamics } \\
\text { Partner relationships } \\
\text { HIV/AIDS stigma \& discrimination }\end{array}$ & $\begin{array}{l}\text { Expectations of women; Media images; Healthy and unhealthy relationships; intimate partner violence; } \\
\text { Gender-role expectations and stereotypes; Impact of gender dynamics on HIV/STI risk; Implications of } \\
\text { age discrepant partners and concurrent partnerships (e.g., the added importance of HTC and PrEP); As- } \\
\text { sertive communication with partners and peers; Changes in community norms to reduce stigma toward } \\
\text { HIV/AIDS, PrEP, and HTC. }\end{array}$ \\
\hline
\end{tabular}

credibility as a resource for HIV/STI prevention and facilitate practice of new communication skills. Additional activities will address conflict negotiation, assertive communication, and strengthening the AGYW-FC relationship. Interventionists will use interactive and experiential activities to address key constructs. The group format promotes structural change by building community norms for prevention (e.g., HTC and PrEP uptake) and reducing HIV stigma. IMARA-SA's goals and motto emphasize strong FC-AGYW relationships, sisterhood, empowerment, and motivation for HIV/STI prevention, and build group cohesion. FC and AGYW will sign a pact to confirm commitment to the program. At the end of session 1, participants will receive homework to complete for session 2. Woven throughout IMARA-SA is the impact of mental health, genderbased violence, and alcohol and drug use on HIVrisk.
Time- and attention-matched control: general health promotion

The HP control group is a time-matched family-based intervention previously delivered to families in SA and translated into Xhosa. The program promotes healthy living by encouraging good nutrition, exercise, and violence reduction (Table 2). Similar approaches will be used by interventionists, including interactive games, videos, worksheets, and group discussion. Like IMARASA, FC and AGYW will meet in separate groups and together to review material and learn about nutrition, substance use, exercise, and other relevant health topics. HIV/AIDS prevention is addressed briefly given the high prevalence in SA.

\section{Contamination}

We will minimize contamination across arms as follows. (1) Interventionists will not overlap, and training will occur separately. (2) Treatment conditions will occupy separate floors at the site to reduce participant contact.

Table 2 Health promotion topics

\begin{tabular}{|c|c|}
\hline Topics & Selected Activities \\
\hline $\begin{array}{l}\text { Media } \\
\text { Literacy }\end{array}$ & $\begin{array}{l}\text { Media influences on body image, weight, beauty; Obesity epidemic in SA and the role of the media (e.g., digital altering, } \\
\text { manipulation) }\end{array}$ \\
\hline $\begin{array}{l}\text { Healthy } \\
\text { Eating }\end{array}$ & Healthy eating; impact of fast food; Nutrition labels; Meal logs to track food choices \\
\hline Violence & $\begin{array}{l}\text { Types and prevalence of violence (gang, domestic, bullying, dating); Links between violence and health; Impact of families and } \\
\text { communities; Tips to prevent violence. }\end{array}$ \\
\hline $\begin{array}{l}\text { Alcohol/ } \\
\text { Drugs }\end{array}$ & $\begin{array}{l}\text { Prevalence of drug and alcohol use among teens; Impact of drugs and alcohol on the brain; Costs of drug/alcohol use on families } \\
\text { and communities; Resources for counseling }\end{array}$ \\
\hline $\begin{array}{l}\text { Physical } \\
\text { Activity }\end{array}$ & $\begin{array}{l}\text { Impact of media and technology on physical activity (e.g., time spent on TV, phones); Benefits of exercise and relation to overall } \\
\text { health and well-being; Practice and planning for one physical activity per day. }\end{array}$ \\
\hline
\end{tabular}


(3) We will assess exposure to IMARA-SA among control participants at 6- and 12-months. (4) We will adjust for exposure in the data analyses.

\section{Study assessments}

AGYW and FC will complete 3-h baseline, 6-, and 12month follow-up assessments, including STI testing and HTC. Surveys will be completed via ACASI. To facilitate retention, we will obtain extensive contact information for participants and three additional individuals who will always know how to reach them.

\section{Primary outcomes}

At 6-month follow-up, we will examine AGYW STI incidence (gonorrhea, chlamydia, and trichomoniasis), PrEP uptake and 1-month supply of medication, and HTC uptake.

Secondary Outcomes: At 12-month follow-up, we will examine AGYW STI incidence (gonorrhea, chlamydia, and trichomoniasis), PrEP prescription and 1-month supply of medication, and HTC uptake. At 6- and 12month follow-up, we will assess AGYW sexual behavior (e.g., condom use, substance use during sex, number of partners, concurrent partners), using the AIDS Risk Behavior Assessment, [82] HIV incidence via HTC, and self-reported adherence to ART and PrEP (where appropriate) using Wilson's 3-item scale [83]. We will use standard cost evaluation methods $[84,85]$ to assess IMARA-SA's costs, including personnel time and nonpersonnel resources (e.g., travel expenses, snacks, incentives, curricular materials).

\section{Mediators and moderators}

We will assess HIV/STI knowledge, attitudes, beliefs, and skills, [86-88] mental health, trauma, and intimate partner violence exposure, [89-92] PrEP knowledge and attitudes, quality and quantity of FC-AGYW communication, [32, 93, 94] parental monitoring, [95] and warmth and closeness in the relationship, [96] gender dynamics and partner communication, [94, 97-99], HIV/AIDS and PrEP stigma, [100], peer influence, [82] and substance use [82]. At 6- and 12-month follow-up, control group participants will indicate if they heard about IMARA-SA (yes/no) and what they heard (openended) to assess contamination.

\section{Retention}

We will collect participant contact information at baseline and the contact information for at least three individuals (i.e., collaterals) who will "always know where they are." We will contact individuals monthly to update our information. We will use multiple methods, including text, email, or phone to reach them. One month before their 6and 12-month follow-up, we will remind them of their next scheduled visit. For AGYW or FC whom we cannot reach, we will visit their homes and contact their collaterals for assistance. We will continue to seek them until the window for their assessment has closed. Timeline

\begin{tabular}{|c|c|c|c|c|c|c|c|c|c|c|c|}
\hline Study Activities & & ear & & & & $\operatorname{ear} 2$ & & & & $\operatorname{ar} 3$ & \\
\hline Quarter & 1 & 2 & 3 & 4 & 1 & 2 & 3 & 4 & 1 & 2 & 34 \\
\hline $\begin{array}{l}\text { Preparation of tools/procedures, } \\
\text { IRB approval }\end{array}$ & $x$ & $x$ & & & & & & & & & \\
\hline Staff recruitment and training & & $x$ & & & & & & & & & \\
\hline $\begin{array}{l}\text { Baseline assessments and } \\
\text { intervention delivery }\end{array}$ & & & $x$ & $x$ & $x$ & $x$ & & & & & \\
\hline 6-month follow-up assessments & & & & & $x$ & $x$ & $x$ & $x$ & & & \\
\hline 12-month follow-up assessments & & & & & & & $x$ & $x$ & $x$ & $x$ & \\
\hline $\begin{array}{l}\text { Data analyses, write-up, and re- } \\
\text { sults dissemination }\end{array}$ & & & & & & & & & $x$ & $x$ & $x$ \\
\hline
\end{tabular}

\section{Data management}

Each participant will be assigned a unique identification (ID) number, which will be used for survey and laboratory data. Most survey data will be collected using Qualtrics, a web-based platform maintained by the University of Illinois at Chicago (UIC). Data that are collected using paper forms will be double entered for accuracy. All paper data will be kept in locked cabinets at the research site. Data will be stored in passwordprotected cloud-based systems and secure servers maintained by UIC and DTHF. Laboratory data will be collected by trained clinic staff and recorded in participant case report forms, which will be stored under lock and key at the research site and routinely transcribed into an electronic spreadsheet. Data will be accessible only to study personnel. Co-PIs will review all external requests to use the data, and data files provided to individuals will be stripped of identifiers. Study investigators will check for the completeness and accuracy of data, and confidentiality of records will be upheld.

\section{Statistical analysis}

We will generate frequencies and summary statistics of predictor and outcome variables to screen and clean the data. We will evaluate randomization by comparing intervention groups on baseline variables using chisquare tests for categorical variables and t-tests or nonparametric Wilcoxon rank-sum tests for continuous variables. In subsequent analyses, we will adjust for predictor variables on which baseline randomization is not successful. We will examine if AGYW who complete the 6- and 12-month assessments differ systematically on baseline data from those lost to follow-up. We will examine correlations among the variables, inspect scale reliabilities to create appropriate scales, and create 
summary scores as appropriate (e.g., mental health problems). We will use models with random intercepts to account for clustering (if needed) and test the significance of clustering of subjects within groups.

We will analyze binary outcomes using logistic regression and continuous outcomes using linear regression. We will test the effect of the intervention on the primary and secondary outcomes and theoretical mediators, adjusting for confounders and the outcome at baseline as additional independent variables. Analyses combining time points will use generalized linear mixedmodels with subject-specific random effects to account for correlation within repeated measurements. We will test an average effect across time points and effects on patterns of change from 6- to 12 -months using interactions with time. Survival analysis methods will assess the effect of the intervention on incident STIs, using extended Cox regression models with fixed and timevarying covariates to estimate univariable and multivariable hazard ratios for associations of exposures with incident STI. Treatment effects may differ systematically depending on various factors, such mental health or substance use. We will test mediator and moderator effects according to Baron \& Kenny [101] and Cohen \& Cohen [102]. We will include interactions between treatment condition and covariates in the GLM, and obtain estimates for regression coefficients of the interaction terms, 95\% confidence intervals, and $p$-values for the hypothesis tests.

We will evaluate the CE of IMARA-SA with respect to STI acquisition, the net cost of the intervention to the health system adjusting for cost savings from STI reduction, and explore HIV incidence where possible. We will conduct individual CE analyses for each STI (i.e., gonorrhea, chlamydia, and trichomoniasis) to compare the $\mathrm{CE}$ of IMARA-SA to interventions that focus on only one STI, as is typical in the limited published literature on STI prevention. The main CE analysis will include all 3 STIs and assess the overall CE of IMARA-SA. In addition, we will conduct two supplementary analyses to estimate: (a) the CE of IMARA-SA when viewed strictly as an HIV prevention intervention; and (b) the CE with all 4 STIs (gonorrhea, chlamydia, trichomoniasis, and HIV). Finally, we will assess the net cost to the health system from implementing IMARA-SA, adjusting for cost savings related to the reduction of STIs. The main outcome for the analyses is the $\mathrm{CE}$ ratio, defined as the incremental cost of the program per infection prevented by the intervention.

\section{Sample size calculation}

Power analyses determined the sample size needed to compare the effect of IMARA-SA and control interventions on AGYW HIV/STI incidence and PrEP and HTC uptake. Because binary outcome variables pose the greatest challenge for power, we evaluated power for STI incidence (yes/no)-our primary outcome-across a range of prevalence estimates over 12-months. All calculations used a 2-sided test with alpha $=.05$. Based on data in the Plus Pills study, [103] using a Cox proportional hazards model with a range of incidence estimates, we will have $\geq 80 \%$ power to detect hazard ratios $\leq 0.5$ for STI incidence ranging from 20 to $30 \%$, even with $25 \%$ attrition. Effect sizes for binary outcomes is given in terms of the relative risk (RR), where $R R=1$ indicates no treatment effect. A $R R<1$ indicates a protective effect of the intervention. With $80 \%$ retention, we will have $\geq 80 \%$ power to detect $R R s \leq 0.38$ when the proportion in the control group is $20 \%$, and RRs $\leq 0.65$ when the proportion in the control group is $50 \%$. We also calculated the standard effect size (d) in standard deviations for group mean comparisons with $80 \%$ power for continuous outcomes, where $\mathrm{d}=0$ is defined as no treatment effect. We will be able to detect a small to medium effect size $(d=0.36)$ even with $75 \%$ retention. Low HIV incidence among AGYW (2.54\%) per year will allow us to explore incidence, but we do not expect sufficient statistical power to test intervention effects on HIV incidence.

\section{Data monitoring}

Data will be monitored by Weststat on an annual basis. A designated monitor will visit the study site to review participant records, consent documents, source documentation, data collection instruments, screening/ enrollment logs, visit checklists, baseline checklists, chart notes, referral forms, recruitment and outcome forms, participant evaluations forms, study blood draws, and survey data base entry. We will also assemble a Data Safety and Monitoring Board, which will review our activities to ensure participant safety and evaluate findings in an interim analysis of the data to determine if the RCT should continue or be stopped.

\section{Adverse event monitoring}

The study team will monitor any potential adverse events or study harms. These will be documented and reported within $24 \mathrm{~h}$ to the study PIs and the IRBs.

\section{Dissemination plans}

Findings will be disseminated through peer-reviewed publications, local and national presentations, and conferences, and to relevant stakeholder groups. The PIs will review and approve all materials prior to dissemination, including written reports and presentations. Data will be placed in a repository for public access once the study is complete and the primary outcome papers are published. 


\section{Discussion}

This study addresses a compelling need for innovative multilevel interventions to improve the HIV prevention and care continuum for AGYW and lays the foundation for sustainability. The ongoing disparity of new infections in SA AGYW [78] requires an expansion of prevention options that address individual, social, and structural drivers, [79] but research on evidence-based interventions with strong evaluation designs and $\mathrm{CE}$ is lacking for AGYW, especially those capitalizing on the strengths and assets of families. We describe herein the design of a RCT of a family-based HIV prevention program, IMARA-SA, to reduce incident STIs and improve uptake of HTC and PrEP among AGYW in South Africa. The intervention draws on a Social Personal Framework [48] which recognizes the multilevel influences of individual, social (family, partner), and structural (stigma, peer norms) characteristics on AGYW HIV-risk and prevention. We hope to extend the evidence base for family-based HIV prevention and uptake of PrEP and HTC among SA AGYW, a population at exceptionally high risk of HIV and STIs and for whom current advances in HIV prevention have not been realized. Importantly, the study responds to urging by the target population for family-based programming. Prior to funding, IMARA-SA was extensively vetted with key stakeholders and the DTHF community advisory boards for approval. This process was essential to ensure study uptake and acceptability broadly, and improve chances for sustainability.

We believe the study design has several strengths. We will leverage FC and the FC-AGYW relationship to support HTC and PrEP uptake and linkage to care (where appropriate). Although AGYW are the primary focus of the program, IMARA-SA targets both FC and AGYW to support one another in prevention efforts. The design offers a combination package that includes behavioral and biomedical intervention strategies and provides onsite access to HTC, PrEP, and STI treatment, eliminating typical barriers to service. Furthermore, we believe that IMARA-SA is responsive to the age, gender, and cultural needs of the population. Although originally designed and tested with African American 14-18-year-old girls in the US, our systematic approach to adaptation for the South African local context increases confidence in its local relevance. This study is among the first to evaluate the impact of a FC-AGYW intervention on HTC and PrEP uptake using a rigorous and culturally adapted trial of sufficient size to detect effects on AGYW STI incidence and explore HIV incidence. We consider it a potential innovation in the HTC and PrEP uptake environment, which given the smooth access to services, close collaboration with clinic partners, and brief intervention format (approximately $10 \mathrm{~h}$ ), is well positioned for scale. IMARA-SA was designed to meet the standard for evidence-based interventions, advance intervention science with SA AGYW, and prepare for sustainability by engaging key stakeholders at the start and documenting the costs.

\begin{abstract}
Abbreviations
AGYW: Adolescent Girls and Young Women; FC: Female Caregivers; SA: South Africa; ARBA: AIDS Risk Behavior Assessment; ACASI: Audio Computer Assisted Self Interview; CDC: Centers for Disease Control and Prevention; HIV: Human Immunodeficiency Virus; HTC: HIV Testing and Counseling; PrEP: Pre-Exposure Prophylaxis; RCT: Randomized Controlled Trial; US: United States; UIC: University of Illinois at Chicago; DTHF: Desmond Tutu Health Foundation; IMARA-SA: Informed, Motivated, Aware, and Responsible Adolescents and Adults- South Africa; HP: Health Promotion; STI: Sexually

Transmitted Infection
\end{abstract}

\section{Acknowledgements}

We would like to thank members of the South African IMARA team for their contribution to study protocol and procedures.

\section{Authors' contributions}

$G D, L G B, M A, E E, D B D, K M, S N$ contributed to the design of all aspects of the study, including the study design and selection of measures. KM supported the development of survey instruments and the design of data collection procedures. GD drafted the manuscript. The manuscript has been read and approved by all authors.

\section{Author's information}

Not applicable.

\section{Funding}

This study is funded by the National Institute of Child Health and Human Development and the Office of Behavioral and Social Sciences Research (UG3HD096875; UH3HD096875). The content is solely the responsibility of the authors and does not necessarily represent the official views of the $\mathrm{NIH}$. $\mathrm{DBD}$, project scientist, not have any ultimate authority over the study activities.

\section{Availability of data and materials}

A de-identified dataset will be made publicly available through the National Institute of Child Health and Human Development (NICHD) Data and Specimen Hub (DASH) https://dash.nichd.nih.gov.

\section{Declarations}

Ethics approval and consent to participate

The study protocol was approved by the Institutional Review Boards of the University of Cape Town (077/2019) and the University of Illinois at Chicago (2018-0709). Female Caregivers and Adolescent Girls and Young Women will complete in-person written informed consent and assent (for Adolescent Girls and Young Women under age 18 years) with trained study staff. Female Caregivers will provide written informed consent for Adolescent Girls and Young Women under age 18 years. This study will be monitored by a Data Safety and Monitoring Board (DSMB), the composition of which has been obtained from the study principal investigator at the lead institution. No criteria for discontinuing or modifying the intervention or trial stopping rules were defined for this study.

Consent for publication

Not applicable.

\section{Competing interests}

The authors declare that they have no competing interests.

\section{Author details}

${ }^{1}$ Center for Dissemination and Implementation Science, Department of Medicine, University of Illinois at Chicago, 818 S. Wolcott, Chicago, IL 60612, USA. ${ }^{2}$ Desmond Tutu HIV Center, Cape Town, South Africa. ${ }^{3}$ Office of 
Behavioral and Social Sciences Research, National Institutes of Health, Bethesda, MD, USA.

\section{Received: 16 July 2021 Accepted: 3 September 2021 Published online: 20 September 2021}

\section{References}

1. Joint United Nations Programme on HIV/AIDS (UNAIDS). Ending AIDS Progress Towards the 90-90-90 Targets. Geneva: Joint United Nations Programme on HIV/AIDS (UNAIDS); 2017.

2. Shisana O, Rehle T, Simbayi L, Zuma K, Jooste S, Zungu N, et al. South African national HIV prevalence, incidence and behaviour survey, 2012. Cape Town: HSRC Press; 2014

3. Lancet: The global HIV/AIDS epidemic — progress and challenges. Lancet 2017, 390(10092):333

4. World Health Organization. Consolidated guidelines on HIV prevention, diagnosis, treatment and care for key populations. Geneva: World Health Organization; 2014

5. AVERT.org. Young People, HIV and AIDS. 2020. https://www.avert.org/ professionals/hiv-social-issues/keyaffected-populations/youngpeople\#footnote5_xtuo2co. Accessed 10 Jan 2021

6. UNICEF. Towards an AIDS-free generation: children and AIDS sixth stocktaking report. In. UNICEF: New York; 2013

7. Adolescents: health risks and solutions. http://www.who.int/mediacentre/fa ctsheets/fs345/en/.

8. Abdool Karim Q, Meyer-Weitz A, Harrison A. Interventions with youth in high prevalence areas. In: Mayer KH, Pizer HF, editors. HIV prevention: A comprehensive approach. London: Academic Press; 2009. p. 407-43.

9. Blankenship KM, Smoyer AB. Between spaces: Understanding movement to and from prison as an HIV risk factor. In: Crime, HIV and health: Intersections of criminal justice and public health concerns: Springer; 2013. p. 207-21.

10. Brawner BM. A multilevel understanding of HIV/AIDS disease burden among African American women. J Obstetr Gynecol Neonatal Nurs. 2014:43(5):633E650. https://doi.org/10.1111/1552-6909.12481

11. Coates TJ, Richter L, Caceres C. Behavioural strategies to reduce HIV transmission: how to make them work better. Lancet. 2008;372(9639):66984. https://doi.org/10.1016/S0140-6736(08)60886-7.

12. Dietrich J, Sikkema K, Otwombe KN, Sanchez A, Nkala B, de Bruyn G, et al. Multiple levels of influence in predicting sexual activity and condom use among adolescents in Soweto, Johannesburg, South Africa. J HIV AIDS Soc Serv. 2013;12(3-4):404-23. https://doi.org/10.1080/15381501.2013.819312.

13. Jackson C, Geddes R, Haw S, Frank J. Interventions to prevent substance use and risky sexual behaviour in young people: a systematic review. Addiction. 2012;107(4):733-47. https://doi.org/10.1111/j.1360-0443.2011.03751.x.

14. Auerbach JD, Parkhurst JO, Caceres CF. Addressing social drivers of HIV/AIDS for the long-term response: conceptual and methodological considerations. Glob Public Health. 2011;6(Suppl 3):S293-309. https://doi.org/10.1080/17441 692.2011.594451.

15. Baird SJ, Garfein RS, Mclntosh CT, Ozler B. Effect of a cash transfer programme for schooling on prevalence of HIV and herpes simplex type 2 in Malawi: a cluster randomised trial. Lancet. 2012;379(9823):1320-9. https:// doi.org/10.1016/S0140-6736(11)61709-1.

16. Chandra-Mouli V, Lane C, Wong S. What does not work in adolescent sexual and reproductive health: a review of evidence on interventions commonly accepted as best practices. Glob Health Sci Pract. 2015;3(3):333-40. https:// doi.org/10.9745/GHSP-D-15-00126.

17. Folkers GK, Fauci AS. Controlling and ultimately ending the HIV/AIDS pandemic: a feasible goal. JAMA. 2010;304(3):350-1. https://doi.org/10.1001/ jama.2010.957.

18. Hankins CA, de Zalduondo BO. Combination prevention: a deeper understanding of effective HIV prevention. AIDS. 2010;24(Suppl 4):S70-80. https://doi.org/10.1097/01.aids.0000390709.04255.fd.

19. Kurth AE, Celum C, Baeten JM, Vermund SH, Wasserheit JN. Combination HIV prevention: significance, challenges, and opportunities. Curr HIV/AIDS Rep. 2011;8(1):62-72. https://doi.org/10.1007/s11904-010-0063-3.

20. Merson MH, O'Malley J, Serwadda D, Apisuk C. The history and challenge of HIV prevention. Lancet. 2008;372(9637):475-88. https://doi.org/10.1016/S014 0-6736(08)60884-3.

21. Padian NS, McCoy SI, Karim SS, Hasen N, Kim J, Bartos M, et al. HIV prevention transformed: the new prevention research agenda. Lancet. 2011 378(9787):269-78. https://doi.org/10.1016/S0140-6736(11)60877-5.
22. Cellum C, Delany-Moretlwe S. HPTN 082: evaluation of daily oral PrEP as a primary prevention strategy for young African women. Paris: International AIDS Society Conference on HIV Science; 2017.

23. Wilson KS, Beima-Sofie KM, Moraa H, Wagner AD, Mugo C, Mutiti PM, et al. "At our age, we would like to do things the way we want: " a qualitative study of adolescent HIV testing services in Kenya. AIDS. 2017;31(Suppl 3): S213-s220. https://doi.org/10.1097/QAD.0000000000001513.

24. Venter WD, Cowan F, Black V, Rebe K, Bekker L-G. Pre-exposure prophylaxis in southern Africa: feasible or not? J Int AIDS Soc. 2015;18(4 Suppl 3):19979. https://doi.org/10.7448/IAS.18.4.19979.

25. Aronowitz T, Rennells RE, Todd E. Heterosocial behaviors in early adolescent African American girls: the role of mother-daughter relationships. J Fam Nurs. 2005;11(2):122-39. https://doi.org/10.1177/1074840705275466.

26. Donenberg GR, Emerson E. Mackesy-Amiti: sexual risk among African American girls: psychopathology and mother-daughter relationships. Consult Clin Psychol. 2011;79(2):153-8. https://doi.org/10.1037/a0022837.

27. Emerson E, Donenberg GR, Wilson HW. Health-protective effects of attachment among African American girls in psychiatric care. J Fam Psychol. 2012;26(1):124-32. https://doi.org/10.1037/a0026352.

28. Jaccard J, Dittus PJ, Gordon W. Parent-adolescent congruency in reports of adolescents sexual behavior and in communications about sexual behavior. Child Dev. 1998;69(1):247-61. https://doi.org/10.1111/j.1467-8624.1998. tb06146.x.

29. O'Donnell L, Stueve A, Durnan R, Myint- $U$ A, Agronick G, San Doval A, et al. Parenting practices, parents' underestimation of daughters' risks, and alcohol and sexual behaviors of urban girls. J Adolesc Health. 2008;42(5): 496-502. https://doi.org/10.1016/j.jadohealth.2007.10.008.

30. Babalola S, Tambashe BO, Vondrasek C. Parental factors and sexual risktaking among young people of cote d'lviore. Afr J Reprod Health. 2005;9(1): 49-65. https://doi.org/10.2307/3583160.

31. Donenberg G, Emerson E, Mackesy-Amiti M, Fletcher F. Sexual risk among African American girls seeking psychiatric care: a social-personal framework. J Consult Clin Psychol. 2018;86(1):24-38. https://doi.org/10.1037/ccp0000270.

32. Dutra R, Miller KS, Forehand R. The process and content of sexual communication with adolescents in two-parent families: associations with sexual risk-taking behavior. AIDS Behav. 1999;3(1):59-66. https://doi.org/10.1 023/A:1025419519668

33. Meschke LL, Bartholomae S, Zentall SR. Adolescent sexuality and parentadolescent processes: promoting healthy teen choices. J Adolesc Health 2002;31(6S):264-79. https://doi.org/10.1016/S1054-139X(02)00499-8.

34. Miller KS, Forehand R, Kotchick BA. Adolescent sexual behavior in two ethnic minority samples: the role of family variables. J Marriage Fam. 1999; 61(2):85-98. https://doi.org/10.2307/353885

35. Miller KS, Fasula A, Dittus P, Wiegand R, Wyckoff S, McNair L. Barriers and facilitators to maternal communication with preadolescents about agerelevant sexual topics. AIDS Behav. 2007;13(2):365-74. https://doi.org/10.1 007/s10461-007-9324-6.

36. Poulsen M, Miller K, Lin C, Fasula A, Vandenhoudt H, Wyckoff S, et al. Factors associated with parent-child communication about HIV/AIDS in the United States and Kenya: a cross-cultural comparison. AIDS Behav. 2009;14(5):108394. https://doi.org/10.1007/s10461-009-9612-4.

37. Whitaker DJ, Miller KS, May DC, Levin ML. Teenage partners' communication about sexual risk and condom use: the importance of parent-teenager discussions. Fam Plan Perspect. 1999;31(3):117-21. https://doi.org/10.2307/2 991693.

38. Adu-Mireku S. Family communication about HIV/AIDS and sexual behavior among senior secondary school students in Accra, Ghana. Afr Health Sci. 2003;3(1):7-14.

39. Crichton J, Ibisomi L, Gyimah SO. Mother-daughter communication about sexual maturation, abstinence and unintended pregnancy: experiences from an informal settlement in Nairobi, Kenya. J Adolesc. 2012;35(1):21-30. https://doi.org/10.1016/j.adolescence.2011.06.008.

40. Dimbuene ZT, Defo BK. Risky sexual behaviour among unmarried young people in Cameroon: another look at family environment. J Biosoc Sci. 2011 43(2):129-53. https://doi.org/10.1017/S0021932010000635.

41. Juma M, Alaii J, Askew A, Bartholomew L, Borne B. Community Perspectives on parental/caregiver communication on reproductive health and HIV with adolescent orphans and non-orphans in Western Kenya. J Child Adolesc Behav. 2015;3(206).

42. Puffer ES, Meade CS, Drabkin AS, Broverman SA, Ogwang-Odhiambo RA Sikkema KJ. Individual- and family-level psychosocial correlates of HIV risk 
behavior among youth in rural Kenya. AIDS Behav. 2011;15(6):1264-74 https://doi.org/10.1007/s10461-010-9823-8.

43. Soon CN, Kaida A, Nkala B, Dietrich J, Cescon A, Gray G, et al. Adolescent experiences of HIV and sexual health communication with parents and caregivers in Soweto, South Africa. SAHARA J. 2013;10(3-4):163-9. https:// doi.org/10.1080/17290376.2014.902769.

44. Peltzer K, Pengpid S. Sexuality of 16-to 17 -years old south Africans in the context of HIV/AIDS. Soc Behav Pers. 2006;34(3):239-56. https://doi.org/1 0.2224/sbp.2006.34.3.239

45. Stevens JW. Smart and sassy: the Strenghts of Inner-City Black girls. New York: Oxford University Press; 2002. https://doi.org/10.1093/acprof:oso/97801 95121643.001.0001.

46. Mbugua N. Factors inhibiting educated mothers in Kenya from giving meaningful sex-education to their daughters. Soc Sci Med. 2007;64(5):107989. https://doi.org/10.1016/j.socscimed.2006.10.008.

47. Kuo C, Atujuna M, Mathews C, Stein DJ, Hoare J, Beardslee W, et al. L KB: developing family interventions for adolescent HIV prevention in South Africa. AIDS Care. 2016;28(Suppl 1):106-10. https://doi.org/10.1080/0954 0121.2016 .1146396$.

48. Donenberg GR, Pao M. Youths and HIV/AIDS: Psychiatry's role in a changing epidemic. J Am Acad Child Adolesc Psychiatry. 2005;44(8):728-47. https:// doi.org/10.1097/01.chi.0000166381.68392.02.

49. HIV/AIDS among US women: Minority and young women at continuing risk. http://www.cdc.gov/hiv/pubs/facts/women.htm.

50. Collins CE, Whiters DL, Braithwaite R. The saved SISTA project: a faith-based HIV prevention program for black woemn in addiction recovery. Am J Health Stud. 2007;22(2):76-82.

51. Cornelius J, Moneyham L, LeGrand S. Adaptation of an HIV prevention curriculum for use with older African American women. J Assoc Nurses AIDS Care. 2008;19(1):16-27. https://doi.org/10.1016/j.jana.2007.10.001.

52. DiClemente RJ, Wingood GM. A randomized controlled trial of an HIV sexual risk-reduction intervention for young African-American women. J Am Med Assoc. 1995;274(16):1271-6. https://doi.org/10.1001/jama.1995.03530160023 028

53. Wingood GM, DiClemente RJ. Enhancing adoption of evidence-based HIV interventions: Promotion of a suite of HIV prevention interventions for African American women. AIDS Educ Prev. 2006;18(Supplement A):161-70.

54. DiClemente RJ, Wingood GM, Harrington KF, Lang DL, Davies SL, Hook EW, et al. Efficacy of an HIV prevention intervention for African American adolescent girls: a randomized controlled trial. J Am Med Assoc. 2004;292(2): 171-9. https://doi.org/10.1001/jama.292.2.171.

55. Brown LK, Hadley W, Donenberg GR, DiClemente RJ, Lescano C, Lang DM, et al. Project STYLE: a multisite RCT for HIV prevention among youths in mental health treatment. Psychiatr Serv. 2014;65(3):338-44. https://doi.org/1 0.1176/appi.ps.201300095.

56. Beauclair R, Kassanjee R, Temmerman M, Welte A, Delva W. Age-disparate relationships and implications for STI transmission among young adults in Cape Town, South Africa. Eur J Contracept Reprod Health Care. 2012;17(1): 30-9. https://doi.org/10.3109/13625187.2011.644841.

57. Cluver L, Boyes M, Orkin M, Pantelic M, Molwena T, Sherr L. Child-focused state cash transfers and adolescent risk of HIV infection in South Africa: a propensity-score-matched case-control study. Lancet Glob Health. 2013;1(6): e362-70. https://doi.org/10.1016/S2214-109X(13)70115-3.

58. Shisana O, Rehle T, Simbayi L, et al. South African national HIV prevalence, HIV incidence, behavior and communication survey. Cape Town: HSRC Press; 2005.

59. Decker MR, Peitzmeier S, Olumide A, Acharya R, Ojengbede O, Covarrubias $L$, et al. Prevalence and health impact of intimate partner violence and nonpartner sexual violence among female adolescents aged 15-19 years in vulnerable urban environments: a multi-country study. J Adolesc Health. 2014;55(6 Suppl):S58-67. https://doi.org/10.1016/j.jadohealth.2014.08.022.

60. Wood K, Jewkes R. "Dangerous" love: Reflection on violence among Xhosa township youth. In: Morrell R, editor. Changing men in southern Africa. New York: Zed Books Ltd; 2001. p. 317-36.

61. O'Leary A, Jemmott JB 3rd, Jemmott LS, Teitelman A, Heeren GA, Ngwane $Z$, et al. Associations between psychosocial factors and incidence of sexually transmitted disease among south African adolescents. Sex Transm Dis. 2015; 42(3):135-9. https://doi.org/10.1097/OLQ.0000000000000247.

62. Dunkle KL, Jewkes RK, Brown HC, Gray GE, McIntryre JA, Harlow SD. Genderbased violence, relationship power, and risk of HIV infection in women attending antenatal clinics in South Africa. Lancet. 2004;363(9419):1415-21. https://doi.org/10.1016/S0140-6736(04)16098-4.

63. Jewkes R, Dunkle K, Nduna M, Levin J, Jama N, Khuzwayo N, et al. Factors associated with HIV sero-status in young rural south African women: connections between intimate partner violence and HIV. Int J Epidemiol. 2006;35(6):1461-8. https://doi.org/10.1093/ije/dyl218.

64. Li Y, Marshall CM, Rees HC, Nunez A, Ezeanolue EE, Ehiri JE. Intimate partner violence and HIV infection among women: a systematic review and metaanalysis. J Int AIDS Soc. 2014;17(1):18845. https://doi.org/10.7448/IAS.17.1.1 8845.

65. Chacko L, Ford N, Sbaiti M, Siddiqui R. Adherence to HIV post-exposure prophylaxis in victims of sexual assault: a systematic review and metaanalysis. Sex Transm Infect. 2012;88(5):335-41. https://doi.org/10.1136/sextra ns-2011-050371.

66. Hatcher AM, Smout EM, Turan JM, Christofides N, Stockl H. Intimate partner violence and engagement in HIV care and treatment among women: a systematic review and meta-analysis. AIDS. 2015;29(16):2183-94. https://doi. org/10.1097/QAD.0000000000000842.

67. Roberts ST, Haberer J, Celum C, Mugo N, Ware NC, Cohen CR, et al. Intimate partner violence and adherence to HIV pre-exposure prophylaxis (PrEP) in African women in HIV Serodiscordant relationships: a prospective cohort study. J Acquir Immune Defic Syndr. 2016;73(3):313-22. https://doi.org/10.1 097/QAl.0000000000001093.

68. Donenberg G, Kendall A, Emerson E, Fletcher F, Bray B, McCabe K. IMARA: a mother-daughter group randomized controlled trial to reduce sexually transmitted infections in adolescent African American women. PLoS One. 2020;15(11):e0239650. https://doi.org/10.1371/journal.pone.0239650.

69. Abdool Karim Q, Abdool Karim SS, Frohlich JA, Grobler AC, Baxter C, Mansoor LE, et al. Effectiveness and safety of tenofovir gel, an antiretroviral microbicide, for the prevention of HIV infection in women. Science. 2010; 329(5996):1168-74. https://doi.org/10.1126/science.1193748.

70. Baeten JM, Donnell D, Ndase P, Mugo NR, Campbell JD, Wangisi J, et al. Antiretroviral prophylaxis for HIV prevention in heterosexual men and women. N Engl J Med. 2012;367(5):399-410. https://doi.org/10.1056/ NEJMoa1108524.

71. Fonner VA, Dalglish SL, Kennedy CE, Baggaley R, O'Reilly KR, Koechlin FM, et al. Effectiveness and safety of oral HIV preexposure prophylaxis for all populations. AIDS. 2016;30(12):1973-83. https://doi.org/10.1097/QAD. 0000000000001145

72. Thigpen MC, Kebaabetswe PM, Paxton LA, Smith DK, Rose CE, Segolodi TM, et al. Antiretroviral preexposure prophylaxis for heterosexual HIV transmission in Botswana. N Engl J Med. 2012;367(5):423-34. https://doi. org/10.1056/NEJMoa1110711.

73. HIV/AIDS. http://www.who.int/mediacentre/factsheets/fs360/en/.

74. PEPFAR: DREAMS innovation challenge fact sheet. In. Edited by PEPFAR; 2016.

75. Auerbach JD, Hoppe TA. Beyond "getting drugs into bodies": social science perspectives on pre-exposure prophylaxis for HIV. J Int AIDS Soc. 2015;18(4 Suppl 3):19983. https://doi.org/10.7448/IAS.18.4.19983.

76. Rhodes SD, Foley KL, Zometa CS, Bloom FR. Lay health advisor interventions among Hispanics/Latinos: a qualitative systematic review. Am J Prev Med. 2007;33(5):418-27. https://doi.org/10.1016/j.amepre.2007.07.023.

77. Tolli MV. Effectiveness of peer education interventions for HIV prevention, adolescent pregnancy prevention and sexual health promotion for young people: a systematic review of European studies. Health Educ Res. 2012; 27(5):904-13. https://doi.org/10.1093/her/cys055.

78. Hardee K, Gay J, Croce-Galis M, Afari-Dwamena NA. What HIV programs work for adolescent girls? J Acquir Immune Defic Syndr. 2014;66(Suppl 2): S176-85. https://doi.org/10.1097/QAl.0000000000000182.

79. Dellar RC, Dlamini S, Karim QA. Adolescent girls and young women: key populations for HIV epidemic control. J Int AIDS Soc. 2015;18(2 Suppl 1): 19408. https://doi.org/10.7448/IAS.18.2.19408.

80. Barnabas RV, Celum C. Bending the curve: maximising impact with focused HIV prevention. Lancet. 2014;384(9939):216-7. https://doi.org/10.1016/S01406736(14)61182-X.

81. Atujuna M, Merrill K, Ndwayana S, Emerson E, Fynn L, Bekker L-G, et al. Engaging female caregivers to improve south African girls' and young womens' sexual and reproductive health outcomes: HIV Research for Prevention Virtual Conference; 2021.

82. Donenberg G, Emerson E, Bryant F, Wilson H, Weber-Shifrin E. Understanding AIDS-risk behavior among adolescents in psychiatric care: 
links to psychopathology and peer relationships. J Am Acad Child Adolesc Psychiatry. 2001;40(6):642-53. https://doi.org/10.1097/00004583-20010600000008.

83. Wilson IB, Lee Y, Michaud J, Fowler FJ Jr, Rogers WH. Validation of a new three-item self-report measure for medication adherence. AIDS Behav. 2016; 20(11):2700-8. https://doi.org/10.1007/s10461-016-1406-x.

84. Gorsky RD. A method to measure the costs of counseling for HIV prevention. Public Health Rep. 1996;111(supplement 1):115-22.

85. Gorsky RD, Teutsch SM. Assessing the effectiveness of disease and injury prevention programs: costs and consequences. MMWR. 1995;RR-10:1-10.

86. Boekhout BA, Hendrick SS, Hendrick C. Exploring infidelity: developing the relationship issues scale. J Loss Trauma. 2003;8(4):283-306. https://doi.org/ $0.1080 / 15325020305882$

87. Kalichman SC, Simbayi L. Traditional beliefs about the cause of AIDS and AIDS-related stigma in South Africa. AIDS Care. 2004;16(5):572-80. https:// doi.org/10.1080/09540120410001716360.

88. Mukoma W, Flisher AJ, Helleve A, Aaro LE, Mathews C, Kaaya S, et al. Development and test-retest reliability of a research instrument designed to evaluate school-based HIV/AIDS interventions in South Africa and Tanzania. Scand J Public Health. 2009;37(Supplement 1):7-15.

89. Kroenke K, Spitzer R, Williams J. The PHQ-9. Validity of a brief depression severity measure. J Gen Intern Med. 2001;16(9):606-13. https://doi.org/10.1 046/j.1525-1497.2001.016009606.x.

90. Prins A, Ouimette P, Kimerling R, Cameron R, Hugelshofer D, Shaw-Hegwer J, et al. The primary care PTSD screen (PC-PTSD): development and operating characteristics. Prim Care Psychiatry. 2003;9(1):9-14. https://doi. org/10.1185/135525703125002360.

91. Spitzer R, Kroenke K, Williams J, Löwe B. A brief measure for assessing generalized anxiety disorder. Arch Intern Med. 2006;166(10):1092-7. https:// doi.org/10.1001/archinte.166.10.1092.

92. WHO: WHO multi-country study on women's health and domestic violence against women: summary report of initial results on prevalence, health outcomes and women's responses. 2005.

93. Miller KS, Levin ML, Whitaker DJ, Xu X. Patterns of condom use among adolescents: the impact of mother-adolescent communication. Am J Public Health. 1998;88(10):1542-4. https://doi.org/10.2105/AJPH.88.10.1542.

94. Miller KS, Kotchick BA, Dorsey S, Forehand R, Ham AY. Family communication about sex: What are parents saying and are their adolescents listening? Fam Plann Perspect. 1998;30(5):218-22 \& 235.

95. Donenberg GR, Wilson H, Emerson E, Bryant FB. Holding the line with a watchful eye: the impact of perceived parental permissiveness and parental monitoring on risky sexual behavior among adolescents in psychiatric care. AIDS Educ Prev. 2002;14(2):138-57. https://doi.org/10.1521/aeap.14.2.138.23 899.

96. Margolies PJ, Weintraub S. The revised 56-item CRPBI as a research instrument: reliability and factor structure. J Clin Psychol. 1977;33(2):473-6. https://doi.org/10.1002/1097-4679(197704)33:2<472:AID-JCLP2270330230>3. $0 . \mathrm{CO} ; 2-\mathrm{S}$.

97. El-Bassel N, Ivanoff A, Schilling RF, Gilbert L, Bourne D, Chen D-R. Preventing HIV/AIDS in drug-abusing incarcerated women through skills-building and social support enhancement: preliminary outcomes. Soc Work Res. 1995; 19(3):131-41.

98. Pulerwitz J, Gortmaker SL, DeJong W. Measuring sexual relationship power in HIV/STD research. Sex Roles. 2000;42(7/8):637-60. https://doi.org/10.1 023/A:1007051506972

99. Wesson P, Lippman S, Neilands T, Twine R, Ahern J, Gomez-Olive X, et al. Multilevel gender-equitable norms and risk of HIV and herpes simplex virus type 2 acquisition among young south African women: a longitudinal analysis of the HIV prevention trials network 068 cohort. J Adolesc Health. 2019;65(6):730-7. https://doi.org/10.1016/j.jadohealth.2019.07.010.

100. Stangl A, Lilleston P, Mathema H, Pilakas T, Krishnaratne S, Sievwright K, et al. Development of parallel measures to assess HIV stigma and discrimination among people living with HIV, community members and health workers in the HPTN 071 (PopART) trial in Zambia and South Africa. J Int AIDS Soc. 2019;22:e25421.

101. Baron RM, Kenny DA. The moderator-mediator variable distinction in social psychological research: conceptual, strategic, and statistical considerations. J Pers Soc Psychol. 1986;51(6):1173-82. https://doi.org/10.1037/0022-3514.51. 6.1173.

102. Cohen J, Cohen P. Applied multiple regression/correlation analysis for the behavioral sciences, 2nd edition edn. New York: Erlbaum; 1983.
103. Gill K, Johnson L, Dietrich J, Myer L, Marcus RF, Wallace M, et al. Acceptability, safety, and patterns of use of oral tenofovir disoproxil fumarate and emtricitabine for HIV pre-exposure prophylaxis in south African adolescents: an open-label single-arm phase 2 trial. Lancet Child Adolesc Health. 2020;4(12):875-83. https://doi.org/10.1016/S2352-4642(20)3 0248-0.

\section{Publisher's Note}

Springer Nature remains neutral with regard to jurisdictional claims in published maps and institutional affiliations.

\section{Ready to submit your research? Choose BMC and benefit from:}

- fast, convenient online submission

- thorough peer review by experienced researchers in your field

- rapid publication on acceptance

- support for research data, including large and complex data types

- gold Open Access which fosters wider collaboration and increased citations

- maximum visibility for your research: over $100 \mathrm{M}$ website views per year

At BMC, research is always in progress.

Learn more biomedcentral.com/submissions 